\title{
How Consistent are Genetic Factors in Explaining Leisure-Time Physical Activity and Sport Participation? The Portuguese Healthy Families Study
}

\author{
Sara Pereira, ${ }^{1}$ Peter T. Katzmarzyk, ${ }^{2}$ Thayse N. Gomes, ${ }^{1,3}$ Robert Elston, ${ }^{4}$ and José Maia ${ }^{1}$ \\ ${ }^{1}$ CIFI2D, Faculty of Sport, University of Porto, Porto, Portugal \\ ${ }^{2}$ Pennington Biomedical Research Center, Louisiana State University, Baton Rouge, LA, USA \\ ${ }^{3}$ Department of Physical Education, Federal University of Sergipe, Sergipe, Brazil \\ ${ }^{4}$ Department of Population and Quantitative Health Sciences, Case Western Reserve University, Cleveland, OH, USA
}

\begin{abstract}
This study investigates how consistent genetic factors are, as measured by heritability estimates $\left(h^{2}\right)$, in the leisure-time physical activity index (LTPAl) and sport participation index (SPI) from early (10-14 yrs) to late adolescence (15-19 yrs). The sample comprises 12,385 subjects from 3,378 Portuguese nuclear families. Height and weight were measured and body mass index (BMI) was calculated, and the LTPAI and SPI were estimated by questionnaire. Socioeconomic status (SES) was assessed by parental occupation. Analyses were done using S.A.G.E. software. Our results showed that $h^{2}$ estimates for the LTPAI and SPI in the two age groups (10-14 yrs and 15-19 yrs) were stable: for the LTPAI, $h^{2}=0.297$ and 0.322 , respectively; and for the SPI, $h^{2}=0.413$ and 0.428 , respectively. Sibling correlations and environmental correlations are higher in the younger age group for both the LTPAI and the SPI. Spousal correlations are higher in the younger age group for the LTPAI and lower for the SPI than the older group. Parent-offspring correlations are similar in both age groups for the LTPAI and SPI. In conclusion, the influence of genetic factors on physical activity and sport participation remains stable across age in adolescence. However, variation in sibling correlations in particular, environmental correlations - was observed. These findings suggest that shared/non-shared environmental factors express different degrees of importance across age. Future intervention programs aiming to promote change in behaviors need to consider these results to bring about positive changes in physical activity and sport participation behaviors within the family setting.
\end{abstract}

Keywords: physical activity, genetic, family, environmental

It is now well established that moderate-to-high levels of physical activity (PA) are positively associated with a variety of psychological and biological health markers (Physical Activity Guidelines Advisory Committee, 2018) in addition to increases in longevity (Bellavia et al., 2013; Yates et al., 2008). The evidence summarized in recent reviews (de Vilhena e Santos et al., 2012; Lightfoot et al., 2017; Lin et al., 2017) indicated that biological/genetic mechanisms explain a significant fraction of the variance in PA. It has been estimated from twin data that genetic factors explain from $0 \%$ (Joosen et al., 2005) to $85 \%$ of the total variance of population PA levels (Stubbe et al., 2005); on the other hand, a smaller range of estimates was obtained from familial (nuclear or extended pedigree) data, ranging from 9\% (Mitchell et al., 2003) to 57\% (Butte et al., 2006).
Sport participation is a specific form of leisure-time PA characterized by systematic training schedules and competitions. Sport participation may elicit moderate-to-high levels of energy expenditure (Patience et al., 2013), and may contribute to the likelihood that children meet recommended levels of PA (Katzmarzyk \& Malina, 1998). Further, sport participation has the potential to positively affect health (Geidne et al., 2013) and, given the known longevity of former athletes, increase life expectancy (Clarke

RECEIVED 20 February 2018; ACCEPTED 12 June 2018. First published online 6 July 2018.

ADDRESS FOR CORRESPONDENCE: José Maia, CIFI2D, Faculty of Sport, University of Porto, Porto 4099-002, Portugal. E-mail: jmaia@fade.up.pt 
et al., 2012; Coate \& Sun, 2013). Apart from research dealing with sport excellence and its enhancing factors in high-level athletes (Bouchard \& Hoffman, 2011), there is limited knowledge about the magnitude of genetic factors governing sport participation in the general population. Available twin data showed that the heritability $\left(h^{2}\right)$ of sport participation ranges from 45\% (Koopmans et al., 1994 ) to $\sim 83 \%$ (Beunen \& Thomis, 1999; Maia et al., 2002). In nuclear family studies, $h^{2}$ is estimated lower than in twin research and ranges from $0 \%$ (Perusse et al., 1989) to $60 \%$ (Butte et al., 2006).

Few studies have addressed the issue of consistency of genetic effects on PA and sport participation across age in children. Stubbe et al. (2005), using data from various twin surveys conducted in the Netherlands, showed that common environmental factors are essentially responsible for sport participation from 13 to 16 years, whereas from 17 to 20 years, a marked shift is present, with genetic factors largely explaining individual differences in sport participation. Using a similar twin sample and the same data analysis strategy, van der Aa et al. (2010) analyzed questionnaire-based exercise behaviors across three age groups (13-14, 15-16, and 17-19 year olds). The variation in sport participation was largely explained by genetic factors (72-85\%) across the three age groups, while environmental influences common to the twin pair (46\%) were only evident in girls aged 13-14 years.

To date, we were only able to identify one study that examined the stability of genetic and environment effects in adolescence, across six different surveys (aged 7-18 years) in exercise behavior during leisure time (Huppertz et al., 2016). Using a twin sample, the authors demonstrated that genetic effects tended to increase across age, and shared environmental effects tended to decrease. To the best of our knowledge, no other study has previously examined the stability of genetic factors in leisure-time PA and sport participation using nuclear families during adolescence.

To the extent that the partition of the phenotypic variability among groups of individuals forming defined family structures (e.g., siblings, parent-offspring, and spouses) allows for the quantification of the stability of genetic effects between and within a particular family structure, the present study aims to investigate how consistent genetic factors are at explaining the variance, particularly as inferred from heritability estimates $\left(h^{2}\right)$ in the leisure-time physical activity index (LTPAI) and the sport participation index (SPI) from early to late adolescence using nuclear family data.

\section{Material and Methods}

\section{Sample}

Between 2006 and 2009, the Portuguese Healthy Families Study (from the Portuguese Estudo das Famílias Portuguesas Saudáveis) enrolled families from the north and cen- tral mainland regions of Portugal, as well as the Azores and Madeira islands. Recruitment occurred mainly through public schools, both preparatory and secondary, where 10to 19-year-old students, who had at least one brother or sister, were asked to become involved in a research project dealing with active and healthy living. Participation was voluntary. In phase 1 , only physical activity (PA) was assessed and 3,378 families offered to participate (12,385 subjects). Given that Portuguese families with three or more children over 10 years of age are very scarce in the Portuguese population (Rosa \& Chitas, 2010), our sample was based on nuclear families with two siblings. Furthermore, we excluded children with physical handicaps, psychological disorders, and chronic diseases that may impair their ability to be physically active or to participate in sports. The families were divided into two groups based on the age of both siblings: 10-14 years and 15-19 years. Families who had siblings in more than one age group were not considered for the analysis. This project was approved by the Faculty of Sport, University of Porto, and governmental school authorities. Informed consent was obtained from parents or legal guardians, and assent from all children and adolescents.

\section{Measures}

Anthropometry. The height and weight of all adolescents were measured using the protocols of Lohman et al. (1988). Height was measured to the nearest $1 \mathrm{~mm}$ with a portable stadiometer (Siber Hegner GPM), and weight with a Seca scale (Model 762) with a precision of $0.1 \mathrm{~kg}$. For parents, a questionnaire was sent home where they self-reported their height and weight, as well as their professional occupation. Body mass index $\left(\mathrm{BMI}=\right.$ weight $[\mathrm{kg}] /$ height $\left.\left[\mathrm{m}^{2}\right]\right)$ was computed for all subjects; they were classified as normal weight, overweight, or obese according to the World Health Organization (WHO, 2000) reference categories for adults and Cole et al.'s (2000) reference categories for children and adolescents.

Physical activity assessment. The Baecke questionnaire (Baecke et al., 1982) was used to assess PA. This has been consistently shown to be a reliable and valid instrument compared with accelerometry (Miller et al., 1994), doublylabeled water (Philippaerts et al., 1999), and other questionnaires (Pereira et al., 1997). The Portuguese version of this questionnaire has been widely used in youth (Antunes et al., 2015; Seabra et al., 2007), twin (Maia et al., 2002), and sibling studies (Pereira et al., 2017; 2018), as well as in family studies (Maia et al., 2014; Santos et al., 2014). The Baecke questionnaire comprises 16 questions that allow the extraction of three component scores: (1) work/school, (2) leisure time, and (3) sport participation. In addition, a total PA index was derived, which is the unweighted sum of the three component indexes. Each component/domain consists of a set of questions scored mostly on a five-point Likert scale, 
where higher scores indicate higher PA levels. In the present study, only two component scores were used: the LTPAI and the SPI. The LTPAI questions are related to modes of transportation to work or school, time spent watching TV, and walking and cycling, whereas the SPI incorporates questions related to type of sport, duration and frequency of practice, and sweating during sport practice. The two indexes range from 1 to 5 . Children and adolescents answered the questionnaire following standard instructions from a team member in their physical education classes, while parents completed the questionnaire at home. Furthermore, all research team members were available to answer any questions from parents.

Parental occupations. Classification of parental occupation was used as a proxy for socioeconomic status (SES). Occupations were categorized into nine groups ( $1=$ highest SES to $9=$ lowest SES) according to the Portuguese National Occupations Classification (Instituto do Emprego e Formação Profissional, 2001). The categories are as follows: $1=$ central administration/politicians and executive directors, $2=$ specialists of intellectual and scientific activities, $3=$ technicians and intermediate-level jobs, $4=$ back-office jobs, $5=$ security and individual services, $6=$ farmer and qualified farm, fish, and forest workers, $7=$ industry and qualified building jobs, $8=$ machine and equipment operators, and $9=$ non-qualified jobs. For all analyses, we clustered the responses into three groups: 0-3 (high SES); 4-6 (medium SES); and 7-9 (low SES).

Statistical analysis. Exploratory analysis and descriptive statistics were computed in SPSS 20, ignoring the sibling relationship; this only trivially biases the reported standard deviations. Variance components and heritability were estimated by maximum likelihood assuming normality, as implemented in the S.A.G.E. (S.A.G.E. - Statistical Analysis for Genetic Epidemiology, 2016) program ASSOC. A linear regression incorporates the covariates age, age ${ }^{2}$, sex, BMI, and SES, and to allow for each family structure, the correlations of the residuals from this linear regression are expressed as functions of estimated variance components. To better approximate normality, each individual's random component, expressed as the sum of shared components and a residual chosen to keep the total variance $\left(\sigma_{T}^{2}\right)$ constant (Elston et al., 1992), undergoes an estimated power transformation; all parameters, including the power parameter, are simultaneously estimated and their standard errors are determined by numerical double differentiation of the likelihood surface. Apart from an individual-specific random component (assumed to be due to measurement error + random environment), the model contains three additional random components that can be shared among two or more relatives: additive polygenic $\left(\sigma_{p}^{2}\right)$, marital $\left(\sigma_{M}^{2}\right)$, and the excess sibling component $\left(\sigma_{S}^{2}\right)$ over and above the additive polygenic component. This last component is thus an environmental component common to siblings, confounded with any non-additive polygenic component, which we assume to be trivially small. Explicitly, we can write the linear mixed model as follows:

$$
y_{i}=\alpha+\beta_{1} c_{1 i}+\beta_{1} c_{2 i}+\ldots+p_{i}+s_{i}+m_{i}+\varepsilon_{i},
$$

where, for the $i$ th individual, $y_{i}$ (SPI or LTPAI) is the quantitative measure, $c_{1 i}, c_{2 i} \ldots$ are the covariates (age, age ${ }^{2}$, sex, $\mathrm{BMI}$, and SES) taken as fixed effects, $p_{i}$ is the random additive polygenic effect, $m_{i}$ is the random marital effect (i.e., an effect common to spouses), $s_{i}$ is the random excess sibling effect (i.e., an effect common to siblings not accounted for by additive polygenic inheritance), and $\varepsilon_{i}$ is the individualspecific random effect.

With the total variance as the denominator, the numerator of heritability is the polygenic variance $\left(h^{2}=\sigma_{p}^{2} / \sigma_{T}^{2}\right)$. Similarly, with the same denominator, the numerators for the residual full sibling, parent-offspring, and marital correlations are, respectively, the full-sibling variance plus half the polygenic variance $\left(\sigma_{S}^{2}+1 / 2 \sigma_{P}^{2}\right)$, half the polygenic variance $\left(1 / 2 \sigma_{P}^{2}\right)$, and the marital component of variance $\left(\sigma_{M}^{2}\right)$. The environmental correlation is calculated using as denominator the total variance minus the polygenic variance, and as numerator the variance of the excess sibling effect, that is, the sibling environmental correlation is $\left(\sigma_{S}^{2}\right) /\left(\sigma_{T}^{2}-\sigma_{P}^{2}\right)$, on the assumption that any non-additive polygenic effect can be ignored. (Note that it is an intraclass correlation because there can be more than two siblings in a sibship and we assume that after regressing out covariates, all the siblings in a sibship have the same mean.) Details of how the transformation - used to obtain a better fit to normality - is performed are given in Bochud (2017). Note that the actual variance components are estimated on the transformed scale and so are not provided in the tables. To test for differences in heritability estimates for the SPI and LTPAI calculated from two independent samples (younger vs. older adolescents), an approximate large sample test was used in which the difference between the two $h^{2}$ estimates was divided by the square root of the sum of their squared standard errors, and the result referred to a standard normal distribution. Analogously, we can test whether any other parameter is different between the younger and older adolescent samples.

Sex-specific familial correlations and their asymptotic standard errors were also estimated on the raw data as well as adjusted for covariates, based on theory developed by Keen and Elston (2003) and Mathew et al. (2011) using the FCOR module of S.A.G.E. (2016).

\section{Results}

Table 1 presents descriptive statistics for all family members. On average, fathers are slightly older than mothers, and siblings show similar ages by gender. As expected, fathers and sons are, on average, taller and heavier than 


\begin{tabular}{|c|c|c|c|c|}
\hline & Fathers $(n=840)$ & Mothers $(n=909)$ & Sons $(n=1,016)$ & Daughters $(n=986)$ \\
\hline Age (years)* & $43.7 \pm 5.5$ & $41.5 \pm 5.5$ & $14.2 \pm 2.5$ & $14.2 \pm 2.6$ \\
\hline Height $(\mathrm{cm})^{*}$ & $171.4 \pm 7.1$ & $159.7 \pm 6.1$ & $162.1 \pm 14.3$ & $156.9 \pm 10.6$ \\
\hline Weight $(\mathrm{kg})^{*}$ & $78.6 \pm 11.6$ & $66.2 \pm 10.9$ & $55.1 \pm 14.9$ & $51.8 \pm 11.6$ \\
\hline BMI $\left(\mathrm{kg} / \mathrm{m}^{2}\right)^{*}$ & $27.1 \pm 4.2$ & $25.9 \pm 4.2$ & $20.6 \pm 3.3$ & $20.9 \pm 3.3$ \\
\hline Overweight (\%) & 50.8 & 37.7 & 17.9 & 18.3 \\
\hline Obese (\%) & 11.5 & 13.4 & 2.7 & 3.1 \\
\hline LTPAl $^{*}$ & $2.1 \pm 0.7$ & $2.6 \pm 0.7$ & $2.9 \pm 0.7$ & $2.6 \pm 0.7$ \\
\hline $\mathrm{SPI}^{*}$ & $2.0 \pm 0.5$ & $1.8 \pm 0.5$ & $2.4 \pm 0.7$ & $2.1 \pm 0.6$ \\
\hline SES (\%) high & 14.1 & & & \\
\hline Medium & 37.2 & & & \\
\hline Low & 48.7 & & & \\
\hline
\end{tabular}

mothers and daughters, respectively. The prevalence of overweight and obesity is similar between sons and daughters, but the prevalence was higher in fathers compared to mothers. On average, fathers are slightly less active than mothers in their LTPAI, but have a slightly higher SPI. Furthermore, siblings are more physically active than their parents, and sons more active than daughters.

Table 2 shows parameter estimates obtained using the S.A.G.E. program ASSOC for LTPAI after adjusting for covariates, namely residual heritability, residual correlations among family members (siblings, parent-offspring, and spouses), and environmental correlations in the two age groups (10-14 and 15-19 years old). The heritability estimates are very significant $\left(p<10^{-6}\right)$, but moderate in their effect size, $h^{2}=0.297 \pm 0.064$ at $10-14$ years and $h^{2}=0.322 \pm 0.063$ at $15-19$ years. Sibling residual correlations are higher in the younger age group $(0.386 \pm 0.035 \mathrm{vs}$. $0.294 \pm 0.044)$ and greater than parent-offspring correlations $(0.149 \pm 0.032,0.161 \pm 0.031)$, and slightly larger than marital correlations $(0.312 \pm 0.047,0.264 \pm 0.048)$. Environmental correlations are low, but higher at 10-14 years old $(0.338 \pm 0.049$ vs. $0.195 \pm 0.066)$. The large sample tests showed no significant difference between the two age groups, in particular for the LTPAI $h^{2}$ estimates $(z=0.278$, $p=.77)$.

Table 3 provides results for the SPI. The heritability estimates are very significant $\left(p<10^{-7}\right)$, but moderate in size: $h^{2}=0.413 \pm 0.068$ at $10-14$ years, and $h^{2}=0.428 \pm 0.068$ at $15-19$ years. The sibling residual correlation is slightly higher in the younger age group $(0.410 \pm 0.037$ vs. $0.316 \pm 0.041)$, larger than the parentoffspring correlation in both age groups $(0.206 \pm 0.034$, $0.214 \pm 0.034)$, and slightly larger than the marital correlation in the younger age group $(0.361 \pm 0.048)$ but slightly smaller in the older age group $(0.408 \pm 0.047)$. Environmental correlations are low, but higher at 10-14 years old $(0.332 \pm 0.061$ vs. $0.178 \pm 0.070)$. No significant difference between the two age groups was given by the approximate large sample test, in particular for the SPI $h^{2}$ estimates $(z=0.156, p=.79)$.
Familial correlations for all possible sex-specific types using the raw data, as well as adjusted for covariates, are presented in Table 4 and were obtained from the S.A.G.E. program FCOR. Correlations between father or mother and siblings are lower than between siblings for the two phenotypes (LTPAI and SPI). Further, correlations are of similar size in families with siblings aged 10-14 and 15-19 years of age. These values remain similar when correlations were calculated using residuals from models adjusted for covariates.

\section{Discussion}

This study examined how consistent genetic factors are for the LTPAI and SPI from early to late adolescence. Results showed moderate LTPAI and SPI heritabilities in both age groups (10-14 and 15-19 yrs). Further, no significant difference was observed in $h^{2}$ estimates in the two age groups, suggesting that the portion of the total variance explained by genes remains consistent across age in adolescence; however, the sets of genes involved remain unidentified. Recent reports have identified some putative effects of specific candidate genes on PA and physical exercise levels, as well as sport participation in different populations (de Geus et al., 2014; de Vilhena e Santos et al., 2012; Lightfoot, 2011). However, the results are unclear, and large-scale replication is needed before any confirmation of these findings can be achieved. For example, in a review by de Vilhena e Santos et al. (2012), the authors reported genome-wide linkage data with markers near different physical activityrelated genes - EDNRB, MC4R, UCP1, FABP2, CASR, and $S L C 9 A 9$. However, no marker was present in more than one study. On the other hand, a review by Lightfoot (2011) revealed two candidate genes that showed consistent associations in the regulation of PA: dopamine receptor $1(D R D 1)$ and helixloop helix 2 (NHLH2). Although the dopamine gene is apparently involved in the regulation of PA, specifically its links to locomotion (Yao et al., 2013), the precise mechanism of how $D R D 1$ regulates the manifold PA expressions is not yet fully known (Lightfoot, 2011). NHLH2 has a 
TABLE 2

Heritability, Residual Familial Correlations, and Environmental Correlations for Leisure-Time Physical Activity Index (LTPAI) of Families Whose Siblings' Age is Within 10-14 or 15-19 Years of Age

\begin{tabular}{|c|c|c|c|c|c|c|}
\hline \multirow[b]{2}{*}{ Parameters } & \multicolumn{3}{|c|}{$10-14$ years old* $\left(n=1,878^{* * *}\right)$} & \multicolumn{3}{|c|}{$15-19$ years old ${ }^{* *}\left(n=1,631^{* * *}\right)$} \\
\hline & Estimate & S.E. & $p$ value & Estimate & S.E. & $p$ value \\
\hline Heritability & 0.297 & 0.064 & $<10^{-7}$ & 0.322 & 0.063 & $<<10^{-6}$ \\
\hline \multicolumn{7}{|c|}{ Residual familial correlations } \\
\hline Sibling & 0.386 & 0.035 & $<10^{-7}$ & 0.294 & 0.044 & $<10^{-7}$ \\
\hline Parent-offspring & 0.149 & 0.032 & $<10^{-5}$ & 0.161 & 0.031 & $<10^{-6}$ \\
\hline Marital (spouse) & 0.312 & 0.047 & $<10^{-7}$ & 0.264 & 0.048 & $<10^{-7}$ \\
\hline Environmental correlation & 0.338 & 0.049 & $<10^{-7}$ & 0.195 & 0.066 & 0.003 \\
\hline
\end{tabular}

TABLE 3

Heritability, Residual Familial Correlations, and Environmental Correlations for Sport Participation Activity Index (SPI) of Families Whose Siblings' Age is Within 10-14 or 15-19 Years of Age

\begin{tabular}{|c|c|c|c|c|c|c|}
\hline \multirow[b]{2}{*}{ Parameters } & \multicolumn{3}{|c|}{$10-14$ years old $*\left(n=1,878^{* * *}\right)$} & \multicolumn{3}{|c|}{$15-19$ years old ${ }^{* *}\left(n=1,631^{* * *}\right)$} \\
\hline & Estimate & S.E. & $p$ value & Estimate & S.E. & $p$ value \\
\hline Heritability & 0.413 & 0.068 & $<10^{-7}$ & 0.428 & 0.068 & $<10^{-7}$ \\
\hline \multicolumn{7}{|c|}{ Residual familial correlations } \\
\hline Sibling & 0.401 & 0.037 & $<10^{-7}$ & 0.316 & 0.041 & $<10^{-7}$ \\
\hline Parent-offspring & 0.206 & 0.037 & $<10^{-7}$ & 0.214 & 0.034 & $<10^{-7}$ \\
\hline Marital (spouse) & 0.361 & 0.048 & $<10^{-7}$ & 0.408 & 0.047 & $<10^{-7}$ \\
\hline Environmental correlation & 0.332 & 0.061 & $<10^{-7}$ & 0.178 & 0.070 & 0.011 \\
\hline
\end{tabular}

Note: *Significant covariates included = age, sex, and BMI.

** Significant covariates included $=$ age and BMI.

*** Total number of pedigree members.

potential functional relationship with PA through its effect on $\beta$-endorphin production as well as an interaction with melanocortin-4 receptor (Good et al., 2008). However, we were not able to find a study that investigated changes in the effects of these candidate genes in different PA manifestations across age.

Notwithstanding what is stated above, available crosssectional family studies using the Baecke questionnaire have reported different $h^{2}$ estimates ranging from 0.17 to 0.63 in the LTPAI, and from 0.19 to 0.68 in the SPI (Choh et al., 2009; Eriksson et al., 2006; Maia et al., 2002; Mustelin et al., 2012; Seabra et al., 2008). Similarly, previous studies focusing on the effect of age on $h^{2}$ also showed varied results. For example, Stubbe et al. (2005) reported that SPI $h^{2}$ estimates increased with age from 0 in two younger age groups (13-14 and 15-16 yrs) to 0.85 in an older age group (19-20 yrs). One possible explanation for this shift in results may be associated with the age period, that is, when youth finish high school and cease to have mandatory involvement in PA through physical education classes, the additive effects of genetic influences and familial environment emerge. On the other hand, and based on adult data, Aaltonen et al. (2010) examined changes in the genetic and environmental influences on the LTPAI in twins over a 6-year follow-up; they showed that genetic influences declined from baseline to follow-up and specific envi- ronmental influences increased from baseline to follow-up. Notwithstanding the use of different methodological strategies among studies that make comparisons difficult, there appears to be a clear fluctuation of the effect sizes of environmental factors in PA across age. For example, previous studies indicated that key life periods have been associated with changes in PA and that PA tends to decline with age (Sallis, 2000), especially during adolescence (Dumith et al., 2011). This PA change may occur as a result of the interaction between individual characteristics and the environment in which the individual lives, learns, works, and plays. For example, D'Haese et al. (2016), using longitudinal data, examined changes in individual and social environmental characteristics relative to PA changes and reported that most individual and social factors became less positive toward PA after the transition to secondary school. Van Der Horst et al. (2007) suggested in their systematic review that PA correlates for both children and adolescents were sex, self-efficacy, and family/parental support. However, attitude, goal orientation/motivation, physical education, and peer support were mostly linked with PA during adolescence. Similarly, the systematic review of Wendel-Vos et al. (2007) on correlates of PA among adults revealed that socio-cultural environmental, social support, and having a companion for PA were mostly important in different PA types and intensities. 


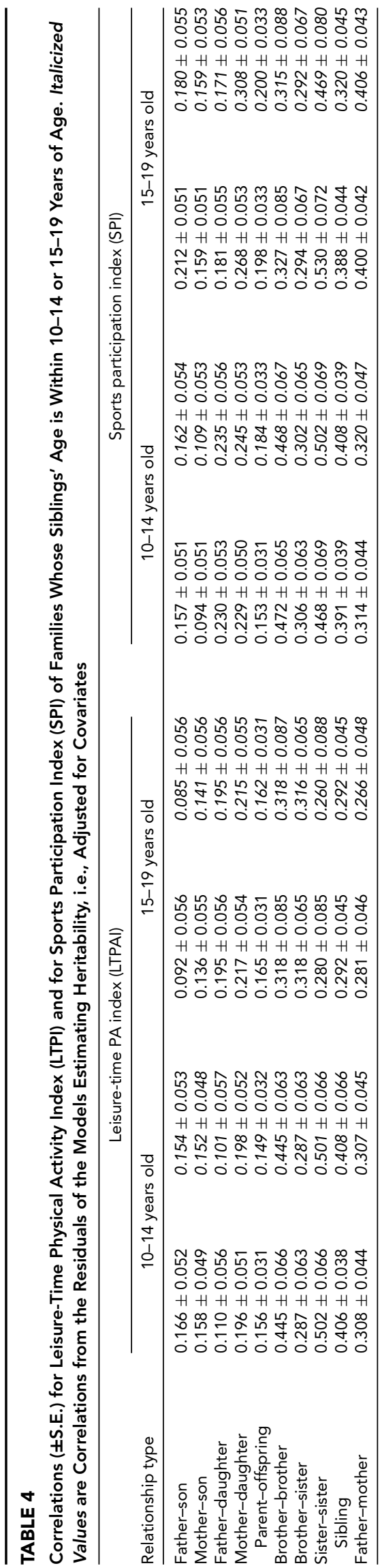

Residual full-sibling correlations after allowing for covariates tend to decrease across age groups for both the LT$\operatorname{PAI}($ from $p=.386$ to $p=.294,10-14$ and $15-19$ age groups, respectively) and the SPI (from $p=.410$ to $p=.316,10-14$ and 15-19 age groups, respectively). These results may be explained by changes in unmeasured environment factors shared among the siblings. Usually during infancy and preadolescence, siblings tend to share common environmental factors, namely their neighborhood and recreational environments, as well as school and common friends (Jago et al., 2017; Maitland et al., 2013; Sullivan et al., 2017); yet, during adolescence and early adulthood, there is growing evidence suggesting that peer relationships (e.g., friends and couples; Barnett et al., 2013; Chung et al., 2017) and intrinsic motivation (Teixeira et al., 2012) are more likely contributors to unshared environmental factors on PA. This is in line with the observation that environmental correlations in the younger group are higher than in the older group in both the LTPAI and the SPI. It is now acknowledged that across the life course - that is, as a person grows and becomes more independent - that she/he tends to create her/his own environment, influenced by all the significant others who are considered important. Additionally, we also showed that parent-offspring correlations are low and that there are practically no changes in their values across age, for both the LTPA and the SPI. Unfortunately, we were not able to identify a study that investigated changes in parentoffspring resemblance across age to make any comparisons. However, previous studies also reported low correlations between parents and their siblings, ranging from 0 to 0.19 (Horimoto et al., 2011; Jacobi et al., 2011; Maia et al., 2014). These results may also suggest that, notwithstanding the transmission of genetic factors that may impact PA levels in offspring, there are probably generation-specific environmental factors promoting higher resemblance among siblings rather than across generations (parents to offspring; De Moor et al., 2011).

In the present study, the LTPA marital residual correlations were $0.312 \pm 0.032$ for the $10-14$ year-old sibling sample and $0.264 \pm 0.048$ for those $15-19$ years old, whereas for the SPI, the correlations were $0.361 \pm 0.048$ and $0.408 \pm 0.047$, respectively. Available spousal correlations from Canada (Simonen et al., 2002), the United States (Mitchell et al., 2003), France (Jacobi et al., 2011), and Brazil (Horimoto et al., 2011) varied substantially from 0.02 (95\% CI $[0.00,0.15])$ with pedometer weekdays' information in French couples, to $0.43 \pm 0.06$ in Canadian spouses using their past-year PA information. Although these spouse correlation discrepancies may be due to different family sampling strategies, diverse covariate adjustment, different statistical techniques used to compute correlations, and the phenotypic expression and instruments used, none of these studies tested the possible processes by which spouses correlate in their PA behaviors. In addition, spousal support, attitudes, number of marriage years, and lifestyle choices of 
spouses can also play important roles (Barnett et al., 2013; Falba \& Sindelar, 2008). Although we do not have any information regarding spouses' number of marriage years in our family data, and no such reference was made in the previous reports, we think that the mutual interaction-influence effect might explain these Portuguese results given their sharing of cultural assets, health beliefs, background behaviors, and their multifaceted experiences as couples. Further, in this study, although an increase in marriage years is implied by siblings' age categories (10-14 vs. 15-19), the correlations were similar.

This study is not without limitations. First, the use of questionnaires to obtain information about PA, sport, or physical exercise levels is susceptible to errors. Yet, selfreport instruments are very often used, especially when sample sizes are relatively large as is the case of twin and nuclear family studies. Additionally, the Baecke questionnaire is frequently used in Portuguese and Brazilian studies with valid and reliable results (Santos et al., 2014; Seabra et al., 2007; Silva et al., 2016). Second, we do not have longitudinal data that investigated chronometric time effects in genetic and environmental links with PA manifold manifestations. Third, no direct measures of environmental factors are available so that direct effects could be properly analyzed and interpreted. This limitation is present in all available studies. Finally, we cannot generalize our results to other populations because of existing environmental and possibly genetic differences.

In conclusion, we showed that LTPA and SPI heritability remains stable across age, from early to late adolescence. This observed familial resemblance is the net result of combined environmental influences that are shared within a family, as well as their genetic endowments. In adolescence, shared environment plays an important role on individual differences in LTPA or SPI. However, the influence of unique environment tends to increase from adolescence to young adulthood. Irrespective of the importance of these findings, there is a need to investigate the complex and dynamic relationships that emerge within and across families followed longitudinally in their varied contexts to more precisely identify the genetic and environment roles in various physical activity manifestations. These are of utmost importance to achieve more efficient health-enhanced behavioral changes and for preventive medicine.

\section{Acknowledgments}

We express our gratitude to all participants in The Portuguese Healthy Families Study. PK is supported, in part, by the Marie Edana Corcoran Endowed Chair in Pediatric Obesity and Diabetes.

\section{Authors' contributions}

JM designed the study and supervised the data collection. JM, SP, and TG organized the data set, cleaned the data, and did the descriptive statistics. JM and RE did the core statistical analysis. SP, PK, RE, TG, and JM wrote the document.

\section{Disclosure of Interests}

None of the authors have any conflicts of interest to report.

\section{References}

Aaltonen, S., Ortega-Alonso, A., Kujala, U. M., \& Kaprio, J. (2010). A longitudinal study on genetic and environmental influences on leisure time physical activity in the Finnish Twin Cohort. Twin Research and Human Genetics, 13, 475481.

Antunes, A. M., Maia, J. A., Stasinopoulos, M. D., Gouveia, E. R., Thomis, M. A., Lefevre, J. A., ... Freitas, D. L. (2015). Gross motor coordination and weight status of Portuguese children aged 6-14 years. American Journal of Human Biology, 27, 681-689.

Baecke, J. A., Burema, J., \& Frijters, J. E. (1982). A short questionnaire for the measurement of habitual physical activity in epidemiological studies. American Journal of Clinical Nutrition, 36, 936-942.

Barnett, I., Guell, C., \& Ogilvie, D. (2013). How do couples influence each other's physical activity behaviours in retirement? An exploratory qualitative study. BMC Public Health, 13, 1197.

Bellavia, A., Bottai, M., Wolk, A., \& Orsini, N. (2013). Physical activity and mortality in a prospective cohort of middleaged and elderly men - A time perspective. International Journal of Behavioral Nutrition and Physical Activity, 10, 94.

Beunen, G., \& Thomis, M. (1999). Genetic determinants of sports participation and daily physical activity. International Journal of Obesity and Related Metabolic Disorders, 23, S55-S63.

Bochud, M. (2017). Estimating heritability from nuclear family and pedigree data. In R. C. Elston (Ed.), Statistical human genetics. Methods and protocols (2nd ed., pp. 195-210). New York, NY: Humana Press.

Bouchard, C., \& Hoffman, E. P. (Eds.) (2011). Genetic and molecular aspects of sports performance. Chichester, UK: Wiley-Blackwell.

Butte, N. F., Cai, G., Cole, S. A., \& Comuzzie, A. G. (2006). Viva la familia study: Genetic and environmental contributions to childhood obesity and its comorbidities in the Hispanic population. American Journal of Clinical Nutrition, $84,646-654$.

Choh, A. C., Demerath, E. W., Lee, M., Williams, K. D., Towne, B., Siervogel, R. M., ... Czerwinski, S. A. (2009). Genetic analysis of self-reported physical activity and adiposity: The southwest Ohio family study. Public Health Nutrition, 12, 1052-1060.

Chung, S. J., Ersig, A. L., \& McCarthy, A. M. (2017). The influence of peers on diet and exercise among adolescents: A systematic review. Journal of Pediatric Nursing, 36, 44-56.

Clarke, P. M., Walter, S. J., Hayen, A., Mallon, W. J., Heijmans, J., \& Studdert, D. M. (2012). Survival of the fittest: 
Retrospective cohort study of the longevity of Olympic medallists in the modern era. BMJ, 345, e8308.

Coate, D., \& Sun, R. (2013). Survival estimates for elite male and female Olympic athletes and tennis championship competitors. Scandinavian Journal of Medicine \& Science in Sports, 23, 722-727.

Cole, T. J., Bellizzi, M. C., Flegal, K. M., \& Dietz, W. H. (2000). Establishing a standard definition for child overweight and obesity worldwide: International survey. BMJ, 320, 1240 1243.

D'Haese, S., Cardon, G., De Bourdeaudhuij, I., Deforche, B., De Meester, F., \& Van Dyck, D. (2016). Changes in individual and social environmental characteristics in relation to changes in physical activity: A longitudinal study from primary to secondary school. International Journal of Behavioral Medicine, 23, 539-552.

de Geus, E. J. C., Bartels, M., Kaprio, J., Lightfoot, J. T., \& Thomis, M. (2014). Genetics of regular exercise and sedentary behaviors. Twin Research and Human Genetics, 17, 262-271.

De Moor, M. H., Willemsen, G., Rebollo-Mesa, I., Stubbe, J. H., De Geus, E. J., \& Boomsma, D. I. (2011). Exercise participation in adolescents and their parents: Evidence for genetic and generation specific environmental effects. Behavior Genetics, 41, 211-222.

de Vilhena e Santos, D. M., Katzmarzyk, P. T., Seabra, A. F., \& Maia, J. A. (2012). Genetics of physical activity and physical inactivity in humans. Behavior Genetics, 42, 559578.

Dumith, S. C., Gigante, D. P., Domingues, M. R., \& Kohl, H. W. 3rd (2011). Physical activity change during adolescence: A systematic review and a pooled analysis. International Journal of Epidemiology, 40, 685-698.

Elston, R. C., George, V. T., \& Severtson, F. (1992). The ElstonStewart algorithm for continuous genotypes and environmental factors. Human Heredity, 42, 16-27.

Eriksson, M., Rasmussen, F., \& Tynelius, P. (2006). Genetic factors in physical activity and the equal environment assumption - The Swedish Young Male Twins Study. Behavior Genetics, 36, 238-247.

Falba, T. A., \& Sindelar, J. L. (2008). Spousal concordance in health behavior change. Health Services Research, 43, 96116.

Geidne, S., Quennerstedt, M., \& Eriksson, C. (2013). The youth sports club as a health-promoting setting: An integrative review of research. Scandinavian Journal of Public Health, 41, 269-283.

Good, D. J., Coyle, C. A., \& Fox, D. L. (2008). Nhlh2: A basic helix-loop-helix transcription factor controlling physical activity. Exercise and Sport Sciences Reviews, 36, 187192.

Horimoto, A. R., Giolo, S. R., Oliveira, C. M., Alvim, R. O., Soler, J. P., de Andrade, M., ... Pereira, A. C. (2011). Heritability of physical activity traits in Brazilian families: The Baependi heart study. BMC Medical Genetics, 12, 155.

Huppertz, C., Bartels, M., de Zeeuw, E. L., van Beijsterveldt, C. E. M., Hudziak, J. J., Willemsen, G., ... de Geus, E. J. C.
(2016). Individual differences in exercise behavior: Stability and change in genetic and environmental determinants from age 7 to 18. Behavior Genetics, 46, 665-679.

Instituto do Emprego e Formação Profissional (2001). National classification of occupations ( 2 nd ed.). Lisboa: IEFP.

Jacobi, D., Caille, A., Borys, J. M., Lommez, A., Couet, C., Charles, M. A., ... FLVS Study Group. (2011). Parentoffspring correlations in pedometer-assessed physical activity. PLoS One, 6, e29195.

Jago, R., Macdonald-Wallis, C., Solomon-Moore, E., Thompson, J. L., Lawlor, D. A., \& Sebire, S. J. (2017). Associations between participation in organised physical activity in the school or community outside school hours and neighbourhood play with child physical activity and sedentary time: A cross-sectional analysis of primary school-aged children from the UK. BMJ Open, 7 , e017588.

Joosen, A. M., Gielen, M., Vlietinck, R., \& Westerterp, K. R. (2005). Genetic analysis of physical activity in twins. American Journal of Clinical Nutrition, 82, 1253-1259.

Katzmarzyk, P. T., \& Malina, R. M. (1998). Contribution of organized sports participation to estimated daily energy expenditure in youth. Pediatric and Exercise Science, 10, 378386.

Keen, K. J., \& Elston, R. C. (2003). Robust asymptotic sampling theory for correlations in pedigrees. Statistics in Medicine, $22,3229-3247$.

Koopmans, J. R., Lorenzo, J. O. V. D., \& Boomsma, D. I. (1994). Smoking and sports participation. In U. Goldbout, U. Faire, \& K. Berg (Eds.), Factors in coronary heart disease (pp. 217-235). Dordrecht: Kluwer Academic.

Lightfoot, J. T. (2011). Current understanding of the genetic basis for physical activity. Journal of Nutrition, 141, 526530 .

Lightfoot, J. T., De Geus, E. J. C., Booth, F. W., Bray, M. S., den Hoed, M., Kaprio, J., ... Bouchard, C. (2017). Biologi$\mathrm{cal} /$ genetic regulation of physical activity level: Consensus from GenBioPAC. Medicine and Science in Sports and Exercise, 50, 863-873.

Lin, X., Eaton, C. B., Manson, J. E., \& Liu, S. (2017). The genetics of physical activity. Current Cardiology Reports, 19, 119.

Lohman, T., Roche, A., \& Martorell, R. (1988). Anthropometric standardization reference manual. Champaign, IL: Human Kinetics Books.

Maia, J., Gomes, T. N., Tregouet, D. A., \& Katzmarzyk, P. T. (2014). Familial resemblance of physical activity levels in the Portuguese population. Journal of Science and Medicine in Sport, 17, 381-386.

Maia, J., Thomis, M., \& Beunen, G. (2002). Genetic factors in physical activity levels: A twin study. American Journal of Preventive Medicine, 23, 87-91.

Maitland, C., Stratton, G., Foster, S., Braham, R., \& Rosenberg, M. (2013). A place for play? The influence of the home physical environment on children's physical activity and sedentary behaviour. International Journal of Behavioral Nutrition and Physical Activity, 10, 99. 
Mathew, G., Song, Y., \& Elston, R. (2011). Interval estimation of familial correlations from pedigrees. Statistical Applications in Genetics and Molecular Biology, 10, Article 11, 1-29.

Miller, D. J., Freedson, P. S., \& Kline, G. M. (1994). Comparison of activity levels using the Caltrac ${ }^{\circledR}$ accelerometer and five questionnaires. Medicine \& Science in Sports \& Exercise, 26, 376-382.

Mitchell, B. D., Rainwater, D. L., Hsueh, W. C., Kennedy, A. J., Stern, M. P., \& Maccluer, J. W. (2003). Familial aggregation of nutrient intake and physical activity: Results from the San Antonio Family Heart Study. Annals of Epidemiology, $13,128-135$.

Mustelin, L., Joutsi, J., Latvala, A., Pietilainen, K. H., Rissanen, A., \& Kaprio, J. (2012). Genetic influences on physical activity in young adults: A twin study. Medicine \& Science in Sports \& Exercise, 44, 1293-1301.

Patience, M. A., Kilpatrick, M. W., Sun, H., Flory, S. B., \& Watterson, T. A. (2013). Sports game play: A comparison of moderate to vigorous physical activities in adolescents. Journal of School Health, 83, 818-823.

Pereira, M. A., FitzerGerald, S. J., Gregg, E. W., Joswiak, M. L., Ryan, W. J., Suminski, R. R., ... Zmuda, J. M. (1997). A collection of physical activity questionnaires for health-related research. Medicine \& Science in Sports \& Exercise, 29, S1S205.

Pereira, S., Katzmarzyk, P. T., Gomes, T. N., Souza, M., Chaves, R. N., Santos, F. K., ... Maia, J. A. (2018). Resemblance in physical activity levels: The Portuguese sibling study on growth, fitness, lifestyle, and health. American Journal of Human Biology, 30, e23061.

Pereira, S., Todd Katzmarzyk, P., Gomes, T. N., Souza, M., Chaves, R. N., Dos Santos, F. K., ... Maia, J. A. (2017). A multilevel analysis of health-related physical fitness. The Portuguese sibling study on growth, fitness, lifestyle and health. PLoS One, 12, e0172013.

Perusse, L., Tremblay, A., Leblanc, C., \& Bouchard, C. (1989). Genetic and environmental influences on level of habitual physical activity and exercise participation. American Journal of Epidemiology, 129, 1012-1022.

Philippaerts, R. M., Westerterp, K. R., \& Lefevre, J. (1999). Doubly labelled water validation of three physical activity questionnaires. International Journal of Sports Medicine, 20, 284-289.

Physical Activity Guidelines Advisory Committee. (2018). Physical activity guidelines advisory committee scientific report. Washington, DC: US Department of Health and Human Services.

Rosa, M. J. V., \& Chitas, P. (2010). Portugal: Os números. Lisboa: Relógio D’Água Editores.

S.A.G.E. (2016). Statistical Analysis for Genetic Epidemiology, Release 6.4: http://darwin.cwru.edu.

Sallis, J. F. (2000). Age-related decline in physical activity: A synthesis of human and animal studies. Medicine \& Science in Sports \& Exercise, 32, 1598-1600.

Santos, D. M., Katzmarzyk, P. T., Diego, V. P., Blangero, J., Souza, M. C., Freitas, D. L., ... Maia, J. A. (2014). Genotype by sex and genotype by age interactions with sedentary behavior: The Portuguese Healthy Family Study. PLoS One, 9, e110025.

Seabra, A. F., Mendonca, D. M., Goring, H. H., Thomis, M. A., \& Maia, J. A. (2008). Genetic and environmental factors in familial clustering in physical activity. European Journal of Epidemiology, 23, 205-211.

Seabra, A. F., Mendonca, D. M., Thomis, M. A., Malina, R. M., \& Maia, J. A. (2007). Sports participation among Portuguese youth 10 to 18 years. Journal of Physical Activity \& Health, 4, 370-380.

Silva, D. R., Fernandes, R. A., Ohara, D., Collings, P. J., Souza, M. F., Tomeleri, C. M., ... Cyrino, E. S. (2016). Correlates of sports practice, occupational and leisure-time physical activity in Brazilian adolescents. American Journal of Human Biology, 28, 112-117.

Simonen, R. L., Perusse, L., Rankinen, T., Rice, T., Rao, D. C., \& Bouchard, C. (2002). Familial aggregation of physical activity levels in the Quebec Family Study. Medicine and Science in Sports and Exercise, 34, 1137-1142.

Stubbe, J. H., Boomsma, D. I., \& De Geus, E. J. (2005). Sports participation during adolescence: A shift from environmental to genetic factors. Medicine and Science in Sports and Exercise, 37, 563-570.

Sullivan, S. M., Broyles, S. T., Barreira, T. V., Chaput, J. P., Fogelholm, M., Hu, G., ... ISCOLE Research Group. (2017). Associations of neighborhood social environment attributes and physical activity among 9-11 year old children from 12 countries. Health Place, 46, 183-191.

Teixeira, P. J., Carraça, E. V., Markland, D., Silva, M. N., \& Ryan, R. M. (2012). Exercise, physical activity, and self-determination theory: A systematic review. International Journal of Behavioral Nutrition and Physical Activity, $9,78$.

van der Aa, N., De Geus, E. J. C., van Beijsterveldt, T. C. E. M., Boomsma, D. I., \& Bartels, M. (2010). Genetic influences on individual differences in exercise behavior during adolescence. International Journal of Pediatrics, 2010, 1-8.

Van Der Horst, K., Paw, M. J., Twisk, J. W., \& Van Mechelen, W. (2007). A brief review on correlates of physical activity and sedentariness in youth. Medicine \& Science in Sports \& Exercise, 39, 1241-1250.

Wendel-Vos, W., Droomers, M., Kremers, S., Brug, J., \& van Lenthe, F. (2007). Potential environmental determinants of physical activity in adults: A systematic review. Obesity Reviews, 8, 425-440.

World Health Organization. (2000). Obesity: Preventing and managing the global epidemic. Geneva, Switzerland: Author.

Yao, F., Walker, P. D., \& MacKenzie, R. G. (2013). A Tet-on system for DRD1-expressing cells. PLoS One, 8, e72681.

Yates, L. B., Djousse, L., Kurth, T., Buring, J. E., \& Gaziano, J. M. (2008). Exceptional longevity in men: Modifiable factors associated with survival and function to age 90 years. Archives of Internal Medicine, 168, 284290. 